\title{
Impact of Partitioning and Oxidative Processing of PAH in Fogs and Clouds on Atmospheric Lifetimes of PAH
}

\author{
Jershon Eagar $^{1}$; Barbara Ervens ${ }^{2,3}$; Pierre Herckes ${ }^{1 *}$
}

1. School of Molecular Sciences, Arizona State University, Tempe, Arizona.

5 2. Cooperative Institute for Research in Environmental Sciences, University of Colorado, Boulder, Colorado.

3. NOAA Earth System Research Laboratory, Chemical Sciences Division, Boulder, Colorado.

*Corresponding author:

10 Pierre.Herckes@asu.edu, Phone: (+1) 480-965-4497, Fax: (+1) 480-965-2747

Highlights:

- Oxy-polycyclic hydrocarbons (PAHs) can substantially partition to the aqueous phase

- Chemical lifetimes of PAHs can be significantly shortened in the presence of fog

15

- Temperature dependencies of partitioning ratios represent huge uncertainty

Key words: PAH, Polycyclic aromatic hydrocarbons, multiphase chemistry, chemical lifetimes 


\section{Abstract}

The importance of the atmospheric aqueous phase of fogs and clouds, for the processing and removal of polycyclic aromatic hydrocarbons (PAHs) is not well known. A multiphase model was developed to determine the fate and lifetime of PAHs in fogs and clouds for a limited set of daytime conditions. The model describes partitioning between three phases (aqueous, liquid organic, and gas), experimental and estimated (photo)oxidation rates. Using a limited set of microphysical and chemical input conditions, the loss rates of PAHs in the complex threephase system are explored.

At $25^{\circ} \mathrm{C}$, PAHs with two, three and four rings were predicted to be primarily in the gas phase (fraction in the gas phase $x_{\mathrm{g}}>90 \%$ ) while five- and six-ring PAHs partitioned significantly into droplets with aqueous phase fractions of 1 to $6 \%$ and liquid organic phase fractions of 31 to 91\%, respectively. The predicted atmospheric chemical lifetimes of PAHs in the presence of fog or cloud droplets $(<8$ hours) were significantly shorter than literature predictions of PAH lifetimes due to wet and dry deposition (1 to 14 days and 5 to 15 months, respectively) and shorter than or equal to predicted lifetimes due to chemical reactions in the gas and organic particulate phases ( 1 to 300 hours). Even though PAH solubilities are $\leq 4 \times 10^{-2} \mathrm{~g} \mathrm{~L}^{-1}$, the results of the current study show that often the condensed phase of fog and cloud droplets cannot be neglected as a PAH sink. 


\section{Introduction}

Polycyclic aromatic hydrocarbons (PAHs) are ubiquitous in the atmosphere. They are formed during the incomplete pyrolysis of organic matter and emitted by vehicles, cigarette smoke, wildfires, fireplaces, smoked foods, and coal power plants (e.g., Rogge et al., 1993; Zhang and Tao, 2009). Many PAHs are classified as suspected human carcinogens and one (benzo[a]pyrene) is a known human carcinogen (U.S. EPA, 2014). The most often studied and most abundant PAHs are fluorene (FLU), acenaphthylene (ACY), anthracene (ANT), fluoranthene (FLT), pyrene (PYR), benzo $[a]$ anthracene (BAA), benzo[e]pyrene (BEP), benzo $[a]$ pyrene (BAP), perylene (PRL), dibenz $[a, h]$ anthracene (DBA), and benzo $[g, h, i]$ perylene

50 (BGP) with typical atmospheric concentrations of 0.002 to $25 \mathrm{ng} \mathrm{m}^{-3}$ while the smallest PAH, naphthalene (NAP), has typical atmospheric concentrations of 20 to $500 \mathrm{ng} \mathrm{m}^{-3}$ (total of gas and particle phases; Fraser et al., 2002; Eiguren-Fernandez et al., 2004; Delgado-Saborit et al., 2013).

PAHs demonstrate semi-volatile behavior with concentrations on the order of $\mathrm{ng} \mathrm{m}^{-3}$ in the atmospheric gas phase (e.g., phenanthrene, PHE $0.15 \mathrm{ng} \mathrm{m}^{-3}$; Delgado-Saborit et al., 2013). Observational studies have shown the partitioning of PAHs in the absence of fogs and clouds (i.e., distribution between the gas and particulate phases) varies with temperature and the molecular weight of the PAH (Fernandez et al., 2002; Eiguren-Fernandez et al., 2004; DelgadoSaborit et al., 2013). For example, Delgado-Saborit et al. (2013) reported PAHs with molecular weights of $<202$ Da to be $>80 \%$ in the gas phase while PAHs $>250$ Da were $30 \%$ or less in the gas phase. The partitioning of PAH between gas and particulate phases also varies with the composition of the particulate phase, especially the soot and organic content of particles (Lohmann and Lammel, 2004). 
When fogs and clouds are present, PAHs are found in the aqueous phase (e.g., BAP: 2 $\times 10^{-7} \mathrm{~g} \mathrm{~L}^{-1}$; Herckes et al., 2002) despite the low water solubilities of PAHs $\left(1.4 \times 10^{-7}\right.$ to 3.2

$65 \times 10^{-2} \mathrm{~g} \mathrm{~L}^{-1}$; Pearlman et al., 1984). Capel et al. (1991) proposed three mechanisms to account for PAH presence in fog water: dissolved organic compounds that act as co-solvents for PAHs, organic compounds acting as surfactants at the droplet surface or in colloids, and PAHs bound to scavenged particles. It was found that filtering fog water isolated most PAHs (Leuenberger et al., 1988) which lead Capel et al. (1991) to conclude that scavenged particles were the largest reservoir of PAHs in fog. Nonetheless, Capel et al. (1990) found that the surface tension in fog water is lower than in pure water, which is a manifestation of surfactant (surface film) and/or cosolvent behavior. Valsaraj $(2004 ; 2009)$ demonstrated PAH adsorption to water surfaces and to surfactant-like organic matter on water surfaces (Donaldson and Valsaraj, 2010; Chen et al., 2011).

There have been few atmospheric PAH multiphase (i.e., more than two phases) studies. Lei and Wania (2004) employed partitioning ratios to predict PAH distribution in clouds. Ehrenhauser et al. (2012) compared the observed PAH distribution in fog with simple predictions using partitioning ratios. While the phase distribution and reactions within a three-phase system are not well known for PAHs, partitioning ratios have been measured and estimated for octanolwater systems (Wang et al., 1986; Hansch et al., 1995; de Maagd et al., 1998), octanol-air systems (Alaee et al., 1996; Harner and Bidleman, 1998; Bamford et al., 1999; Odabasi et al., 2006; Ma et al., 2010), and water-air systems, i.e., Henry's law constants (ten Hulscher et al., 1992; Reza and Trejo, 2004; Sander 2015). (Photo)Chemical degradation rate constants of many PAHs in the various phases have been measured or calculated (Calvert et al., 2002) and the 85 products of PAH oxidation reactions have been reported in the gas (Helmig et al., 1992; Helmig 
and Harger, 1994; Lane et al., 1996; Mihele et al., 2002; Wang et al., 2007; Lee and Lane, 2010), aqueous (Sigman et al., 1996; Mallakin et al., 2000; Kong and Ferry, 2003; Woo et al., 2009; Sanches et al., 2011) and organic phases (Jang and McDow, 1997; Fioressi and Arce, 2005). To the best of the authors' knowledge, only one study has published PAH photochemical degradation rate constants in organic / aqueous liquid mixtures (Grossman et al., 2016) and this was limited to ANT and PYR. The conclusion of their study was that ANT and PYR processing in the aqueous phase is faster than in a liquid organic phase and thus chemical reactions in the aqueous phase should be considered in identifying chemical sinks of PAHs, in addition to physical deposition processes. The atmospheric oxidation of PAHs yields oxy-PAH products (PAHs with one or more oxygen atoms in carboxyl groups and/or as heteroatoms in the ring) which are more soluble than parent PAHs (Delgado-Saborit et al., 2013). This conversion affects the phase distribution of PAHs and therefore their atmospheric lifetimes.

Previously, PAH processing in the atmospheric aqueous phase was considered to be negligible (Lohmann and Lammel, 2004) due to the low solubility of PAHs. Gas phase PAH reactions and heterogeneous reactions on particulate matter surfaces were considered the main sink of PAHs where atmospheric lifetimes range from 1 to $300 \mathrm{hr}$ (Keyte et al., 2013). It has been suggested that dry deposition is the main physical (i.e., non-chemical) loss process of PAHs and therefore their atmospheric lifetime (1 to 14 days) is constrained by the particle lifetime (about 7 days) (Bidleman, 1988; Škrdlíková et al., 2011). Removal by wet deposition (rain) is 105 considered to be at least ten times less efficient than dry deposition (5 to 15 months) (Škrdlíková et al., 2011).

The multiphase system (organic, gas, and aqueous phases) of clouds and fogs is very complex. Multiple organic phases may exist simultaneously which are not necessarily in equilibrium with 
the aqueous phase. It has been shown that small PAH amounts in droplets might be associated 110 with soot and therefore does not reside on a droplet surface (e.g., Walters and Luthy,1984, Lohmann and Lammel, 2004; Koelmans et al., 2006; Bedjanian and Nguyen, 2010). However, given the low scavenging efficiency of soot (typically $<10 \%$, Herckes et al., 2013) this effect can be considered minor. The incorporation of PAHs into clouds (interstitial particles or cloud droplets) strongly depends on their emission sources (co-emission with particles) and their physicochemical parameters (solubility, molecular weight etc.).

During droplet nucleation and scavenging processes, it is unknown what fraction of PAHs bound to PM (particulate matter) will dissolve into the atmospheric aqueous phase. Open questions remain as to the role of surface films on PAH uptake by fog and cloud droplets and whether PAHs incorporate into or onto atmospheric droplets. This is in part due to analytical constraints of sample size and PAH detection limits. Many studies of PAH uptake from the gas phase by surface films on water have employed planar or cylindrical surfaces which do not have the same surface area to volume ratios as cloud droplets (Moza et al., 1999; Chen et al., 2006; Chen et al., 2011). A few studies of PAH uptake from the gas phase have employed $92 \mu \mathrm{m}$ droplets (Raja and Valsaraj, 2006) or modeled $1000 \mu \mathrm{m}$ droplets (Ma et al., 2013) which were greater than the $\sim 5$ to $20 \mu \mathrm{m}$ droplets typically found in fogs and clouds (Zak, 1994). Other studies have employed concentrations of PAHs far exceeding those found in typical fogs and clouds (Kahan and Donaldson, 2007; Chen et al., 2011; Styler et al., 2011).

In the current study, we summarize partitioning ratios and oxidation rate constants of PAHs and oxy-PAHs. This data is included in a three-phase box model in order to compare the simultaneous loss rates in the gas, liquid organic and aqueous phases and to assess the role of each phase as a chemical sink of PAHs and oxy-PAHs during the daytime. We neglect possible 
processing during the nighttime due to the significant lack of data of corresponding (e.g., ${ }^{\circ} \mathrm{NO}_{3}$ ) rate coefficients and product yields in all three phases. Simulations are performed for a limited set of fog and chemical conditions (liquid water content, initial concentrations of chemical

135 species in the multiphase system, etc.) as we consider the current study as a starting point to explore the chemical behavior of PAHs in the complex water-organic-gas system.

\section{Data Review}

\subsection{Partitioning ratios to describe the distribution between gas, aqueous and organic phases}

Three constants describe the equilibrium partitioning between the gas, organic and 140 aqueous phases, respectively. The dimensionless 1 -octanol/water partitioning ratio, $K_{\mathrm{OW}}$ (Eq. 1), describes the equilibrium distribution of $\mathrm{PAH}$ concentrations between water and octanol $\left([\mathrm{PAH}]_{\mathrm{aq}}\right.$ and $[\mathrm{PAH}]_{\mathrm{org}}$, respectively). 1-octanol is assumed in the present study as a proxy of a liquid organic (org) phase in fog and cloud droplets (Finlayson-Pitts and Pitts, 1999); $K_{\mathrm{OW}}$ and can be considered a measure of hydrophobicity.

$145 \quad K_{\mathrm{OW}}=\frac{[\mathrm{PAH}]_{\mathrm{org}}}{[\mathrm{PAH}]_{\mathrm{aq}}}$

The dimensionless octanol/air partitioning ratio $K_{\mathrm{OA}}$ describes the ratio of $\mathrm{PAH}$ concentrations in $1-$ octanol and in air $[\mathrm{PAH}]_{\mathrm{g}}$ :

$K_{\mathrm{OA}}=\frac{[\mathrm{PAH}]_{\mathrm{org}}}{[\mathrm{PAH}]_{\mathrm{g}}}$

The Henry's law constant $H\left[\mathrm{~mol} \mathrm{~L}^{-1}\right.$ atm $\left.^{-1}\right]$ describes gas-aqueous partitioning with $p_{\mathrm{PAH}}$

150 [atm] being the partial pressure of PAHs in the gas phase:

$H=\frac{[\mathrm{PAH}]_{\mathrm{aq}}}{p_{\mathrm{PAH}}}$ 
Literature values of $K_{\mathrm{OW}}, K_{\mathrm{OA}}$, and $H$ are summarized in Table $\mathrm{S} 1 . H$ can be calculated with the law for ideal gases, $K_{\mathrm{OW}}$, and $K_{\mathrm{OA}}$ where $R$ is the universal gas constant $[0.08206 \mathrm{~L}$ atm $\left.\mathrm{mol}^{-1} \mathrm{~K}^{-1}\right]$, and $T$ is the absolute temperature $[\mathrm{K}]$ :

$155 \quad H^{*}=\frac{K_{\mathrm{OA}}}{K_{\mathrm{OW}} R T}$

The asterisk superscript is included in Eq. 4 to distinguish $H$ for pure-water / gas systems (either measured or calculated) from calculated $H^{*}$ based on $K_{\mathrm{OW}}$ and $K_{\mathrm{OA}}$. Values for $H^{*}$ together with literature $H$ are summarized in Table S1.

When literature partitioning ratios are unavailable they can be estimated with the U.S. EPA's EPISuite (2015), which is a collection of software for the prediction of chemical release potential in the environment. The EPISuite $K_{\mathrm{OW}}$ estimation methodology is based on dividing a molecule into fragments followed the summation of fragment coefficients with correction factors for intramolecular effects. EPISuite estimates $K_{\mathrm{OA}}$ through a rearrangement of Eq. 4 using $K_{\mathrm{OW}}$ and literature $H$. When unavailable, EPISuite estimates $H$ from the sum of bond contributions and correction factors.

There is an internal inconsistency between the three partitioning ratios $H, K_{\mathrm{OW}}$, and $K_{\mathrm{OA}}$ which has been attributed to octanol and water being mutually partially soluble (Ma et al., 2010). $K_{\mathrm{OW}}$ is measured in octanol that is 'wet' or saturated with water and in water that is saturated with octanol. $H$ is measured in an ideal aqueous solution and $K_{\mathrm{OA}}$ is measured in 'dry' or anhydrous octanol (Harner and Mackay, 1995; Goss, 2004). However, in atmospheric systems, the organic phase is not anhydrous and the aqueous phase is not free of organic compounds. Since the aim of the current work is to predict the distribution of PAHs when all three phases are present, it is desirable to employ constants that are measured in octanol-saturated water and water-saturated octanol. $K_{\mathrm{OW}}$ meets this requirement and is selected as an independent parameter 
175 in Eq. 4. Of the remaining two partitioning ratios, $K_{\mathrm{OA}}$ and $H$, neither is internally consistent with

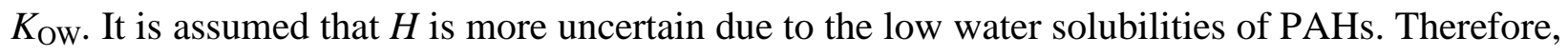
$K_{\mathrm{OA}}$ is selected as an independent variable and $H^{*}$ as the dependent variable in Eq. 4.

$H^{*}$ is systematically higher than $H$ (Fig. S1). The magnitude of the inconsistency has been reported to be negligible for NAP (two-rings) but one order of magnitude for IND (six180 rings; converted from the magnitude of $K_{\mathrm{OW}}$ difference; Ma et al., 2010). This discrepancy between $H$ and $H^{*}$ occurs since the water phase in $K_{\mathrm{OW}}$ is octanol-saturated, which increases PAH solubility, decreases $K_{\text {Ow }}$ and, therefore, increases $H^{*}$. Nevertheless, $H^{*}$ are approximately within an order of magnitude of literature $H$ and EPISuite $H$ (Table S1 and Fig. S1). This is considered adequate for PAHs since there are notable (half an order of magnitude) uncertainties

185 in $H, K_{\mathrm{OW}}$ and $K_{\mathrm{OA}}$ as well as the 'wet octanol' and 'dry octanol' inconsistency. For example, at $25^{\circ} \mathrm{C}$ the calculated $H^{*}$ of PHE, $52 \pm 29 \mathrm{Matm}^{-1}$, is about a factor of two higher than its literature value $\left(H, 21 \pm 4 \mathrm{M} \mathrm{atm}^{-1}\right.$; Alaee et al., 1996). Here, the uncertainty in the $H^{*}$ of PHE is estimated as the propagation of $K_{\mathrm{OW}}$ and $K_{\mathrm{OA}}$ uncertainties: $\log _{10}^{-1}(4.57 \pm 0.08)$ (de Maagd et al., 1998 ) and $\log _{10}^{-1}(7.68 \pm 0.33)$ (Odabasi et al., 2006) respectively; the uncertainty in $H$ is estimated as the 190 standard error of prediction from the data given in Alaee et al. (1996).

Many EPISuite $H$ values fall on the 1:1 line with $H^{*}$ (open boxes in Fig. S1) since EPISuite uses Eq. 5 (a rearrangement of Eq. 4) to estimate $K_{\mathrm{OA}}$ where no literature value exists:

$K_{\mathrm{OA}}=K_{\mathrm{OW}} R T H$ 
Kinetic rate constants $k$ are listed for the oxidation reactions of gas-phase PAHs (Table S2) with various oxidants, which include the hydroxyl radical $k\left({ }^{\circ} \mathrm{OH}, \mathrm{g}\right)$, ozone $k\left(\mathrm{O}_{3}, \mathrm{~g}\right)$, and atomic oxygen $k\left(\mathrm{O}\left({ }^{3} \mathrm{P}\right), \mathrm{g}\right)$. Measurements of the gas-phase oxidation kinetics for PAHs with four or more rings (BAA, $\mathrm{CHY}, \mathrm{BAP}$ etc.) and most oxy-PAHs are largely absent from the literature due to their lower volatility (Calvert et al., 2002). EPISuite gas-phase rate constants are used when literature values are unavailable (Table S2).

Two pseudo-first order photooxidation rate constants are applied for the condensed phases: the photooxidation rate constant in bulk water $k(\mathrm{aq})$ and in liquid organic phase $k(\mathrm{org})$. Aqueous phase oxidizing agents are known to include ${ }^{\circ} \mathrm{OH}$ and singlet oxygen, $\mathrm{O}_{2}\left({ }^{1} \Delta_{\mathrm{g}}\right)$, both of which can be formed from the reaction of ground-state dissolved oxygen $\mathrm{O}_{2}(\mathrm{aq})$ with photoexcited PAHs; thus aqueous PAHs photodegrade in a self-catalyzing process when $\mathrm{O}_{2}(\mathrm{aq})$ is present (Pierlot and Aubry, 1997; Miller and Olejnik, 2001; Kong and Ferry, 2003; Clark et al., 2007). When liquid organic phases are in contact with water, $\mathrm{O}_{2}\left({ }^{1} \Delta_{\mathrm{g}}\right)$ is an important PAH oxidant; however, in anhydrous liquid organic phases, PAH removal is slower and/or occurs by 210 different reaction pathways (Plata et al., 2008). Water molecules may stabilize the polar transition states or radical intermediates of the reaction of PAHs with $\mathrm{O}_{2}\left({ }^{1} \Delta_{\mathrm{g}}\right)$ (Plata et al., 2008). Oxidation may occur to a greater extent in the aqueous phase while the liquid organic phase acts as a PAH sink, supplying PAH to the aqueous phase in accordance with Le Châtelier's principle (Grossman et al., 2016).

There are few PAH $k$ (org) measured in a liquid organic phase (Table S2): ANT and PYR in 1-octanol (Grossman et al., 2016), ANT and PYR in methanol (Grossman et al., 2016), and BAA, CHY, BAP, and BEP in toluene (Plata et al., 2008). In addition, photooxidation rates of PAHs have been reported on the waxy epidermidis of spruce needles (Niu et al., 2003). The 
$k$ (org) in 1-octanol, methanol, and toluene are within an order of magnitude of $k$ (needle epidermidis) for ANT, PYR, BAA, CHY, BAP and BEP (Table S2; Fig. S2). Grossman et al. (2016) reported a systematic decrease in $k$ (org) for decreasing solvent polarity, which is seen in Fig. S2 where $k(1-$ octanol $)$ is five to seven times smaller than $k$ (methanol).

Irradiation intensity also affects $k($ org $)$ as evidenced in Fig. S2 where $k(1-$ octanol $)$ is about five to seven times smaller than $k$ (toluene) notwithstanding toluene being less polar than 1-octanol: the intensity employed for the experiments in toluene by Plata et al. (2008) was close to $888 \mathrm{~W} \mathrm{~m}^{-2}$ while Grossman et al. (2016) employed about $17 \mathrm{~W} \mathrm{~m}^{-2}$ in methanol and Niu et al. (2003) reported a mean irradiation intensity of $620 \pm 50 \mathrm{~W} \mathrm{~m}^{-2}$ for the experiments on spruce needles.

$k$ (org) for ten PAHs are calculated as a function of the linear regression of $k$ (toluene) vs. $k$ (needle epidermidis) (see best-fit 1/7.2 line in Fig. S2). For NAP, ACP, BAU, BBU, and RET neither a literature $k($ org) nor an estimated $k($ org $)$ is currently available; therefore, the photooxidation in the liquid organic phase for those five PAHs is not included in the model (Section 4).

The major products of PAH (photo)oxidation are monocyclic aromatics and non-aromatic organic compounds (Moza et al., 1999; Mallakin et al., 2000; Kong and Ferry, 2003; Woo et al., 2009). Polycyclic aromatic products, i.e., oxy-PAHs are minor products of PAH photo(oxidation) and have molar yields $\left(Y_{\mathrm{m}}\right)$ of a few percent or less. Literature $Y_{\mathrm{m}}$ are consistently $<3 \%$ for reactions with the three gas-phase oxidants and in the condensed phases: $Y_{\mathrm{m}}\left({ }^{\circ} \mathrm{OH}, \mathrm{g}\right), Y_{\mathrm{m}}\left(\mathrm{O}_{3}, \mathrm{~g}\right), Y_{\mathrm{m}}\left(\mathrm{O}\left({ }^{3} \mathrm{P}\right), \mathrm{g}\right), Y_{\mathrm{m}}(\mathrm{aq})$, and $Y_{\mathrm{m}}(\mathrm{org})$ (Table $\left.\mathrm{S} 3\right)$. An estimate of $1 \%$ is used for 240 products of these oxidation reactions with the native-ring backbone intact while $0.1 \%$ is used for ring-rearranged / ring-opened products for reactions without literature $Y_{\mathrm{m}}$ (Fig. S3; Table S3). 
There are no literature values available for such yields; therefore, additional measurements are sorely needed to refine these estimates. It is noteworthy that the yields of nitro-PAH (not investigated here) might be higher than those of oxy-PAH (Atkinson and Arey, 1994). The 245 solubility of nitro-PAHs is often smaller than that of oxy-PAHs; therefore they are expected to partition less into the aqueous phase.

Some values of $Y_{\mathrm{m}}$ are based on irradiation spectra that are not atmospherically representative, that is, the setup did not include filters to correct the UV irradiation intensity spectrum to be representative of sunlight at the surface of the Earth (e.g., UV lamps without air 250 mass filters; Woo et al., 2009; Sanches et al., 2011). In those instances, the same products are assumed here while the yield is not. Probable products and estimated yields are indicated by parentheses in Table S3. The molecular structures of PAHs and their oxidation products (oxyPAHs) are given in Fig. S3.

$Y_{\mathrm{m}}\left(\mathrm{NO}_{3}, \mathrm{~g}\right)$ of $\mathrm{PAH}$ oxidation to oxy-PAH products is currently only available for 255 PHE $\rightarrow$ oPHE2 (33 $\pm 9 \%)$ and is more than an order of magnitude higher than other $Y_{\mathrm{m}}$ (Wang et al., 2007). It is assumed here that ${ }^{\circ} \mathrm{NO}_{3}$ reacts with PAHs in a way that suppresses somewhat the fragmentation of PAHs into monocyclic and acyclic compounds thus increasing the production of oxy-PAHs. Since we cannot estimate other ${ }^{\circ} \mathrm{NO}_{3}$ rate constants and yields for other PAHs based on this single value, we do attempt to include any ${ }^{\circ} \mathrm{NO}_{3}$ reactions in our model and we limit our simulations to daytime conditions. It is expected that under such conditions ${ }^{\circ} \mathrm{OH}$ and $\mathrm{O}_{3}$ reactions will dominate for which more reliable, systematic estimates can be made for rate constants and yields based on a larger data set. Choosing different ${ }^{\circ} \mathrm{OH}$ or $\mathrm{O}_{3}$ concentrations, respectively, would not lead to different conclusions because the loss rates are in all three phases 
are affected to the same extent but the relative importance of the losses in each phase would not 265 be affected.

\section{Model Description}

A box model is applied to calculate PAH equilibrium partitioning and processing in three phases: gas, aqueous, and liquid organic (Fig. 1). The model includes monodispersed $10 \mu \mathrm{m}$ diameter water droplets with constant phase volume ratios $(\phi)$. The assumed drop radius is well within the range of drop sizes that were reported by Zak (1994) for a variety of fogs.

The temperature and $\mathrm{pH}$ are held constant with $\mathrm{T}=25^{\circ} \mathrm{C}$ and $\mathrm{pH}=6$, respectively over the simulation time of three hours. During each time step (1 s), the PAH and oxy-PAH 275 concentrations change due to chemical reactions. Following that, the new equilibrium concentrations of PAHs and oxy-PAHs between all three phases are calculated (Appendix 1, Supplemental Material). The assumption of equilibrium has been used in many models (Lei and Wania, 2004 and references therein; Lohmann and Lammel, 2004; Lammel et al., 2009) even though equilibrium may not always exist. 


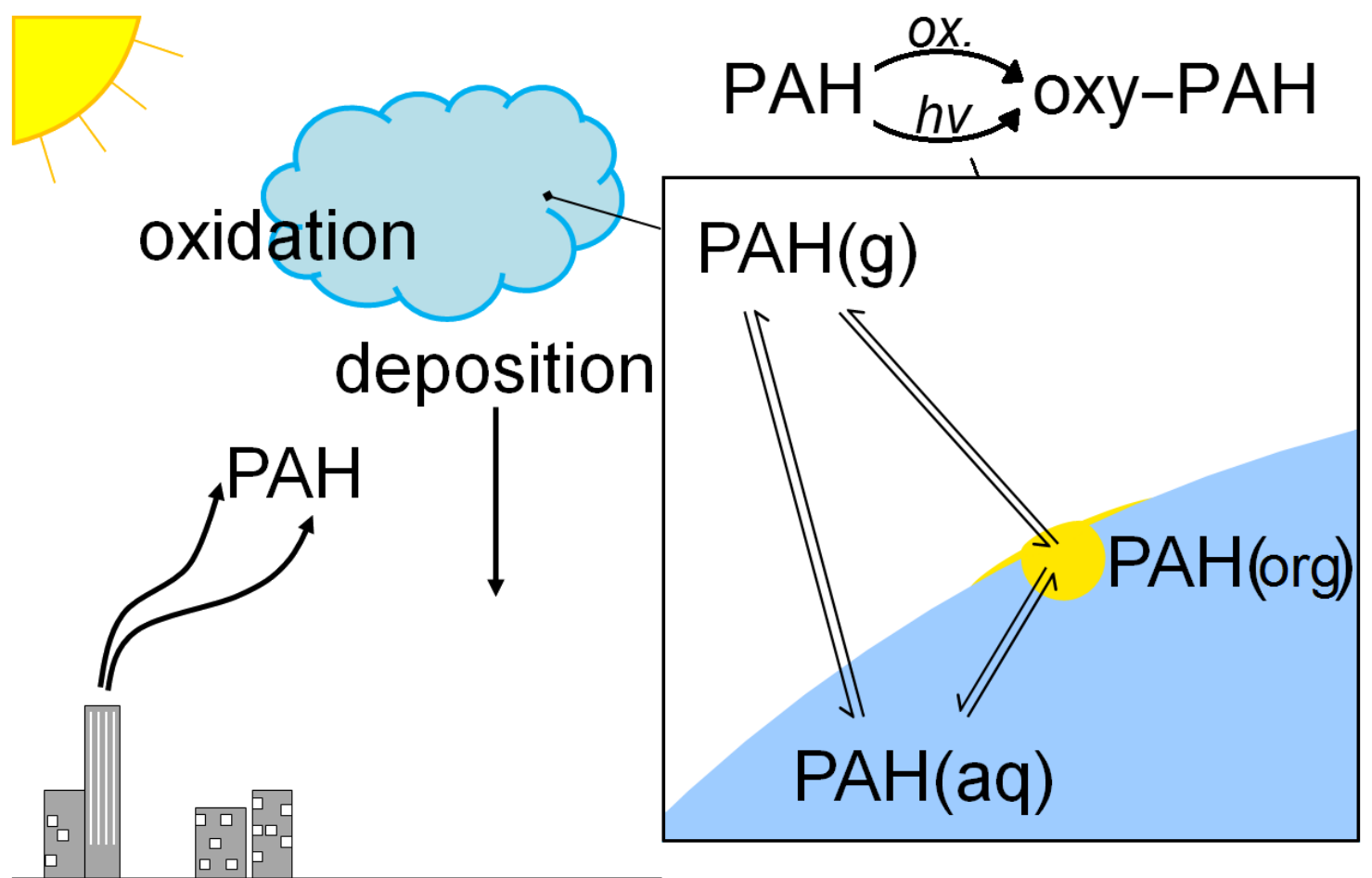

Fig. 1. Schematic of the PAH multiphase (gas, aqueous, liquid organic) (photo)oxidation model.

The model is initialized with gas phase concentrations of oxidants (Table 1); these concentrations are held constant throughout the simulations and reflect typical oxidant levels for remote daytime conditions $\left({ }^{\circ} \mathrm{OH}, \mathrm{O}^{3} \mathrm{P}, \mathrm{O}_{3}\right)$. The ${ }^{\circ} \mathrm{OH}$ concentration of $3 \times 10^{6} \mathrm{~cm}^{-3}$ can be considered typical for daytime conditions. While oxidant concentrations might vary over an order of magnitude or more, the authors emphasize that the concentrations in Table 1 represent average values typical for urban daytime conditions. In clouds/fogs, they might be reduced or enhanced, depending on the density of clouds (Ervens, 2015).Given the fact that we only 290 simulate daytime conditions, it can be expected that ${ }^{\circ} \mathrm{NO}_{3}$ reactions do not play a significant role. We exclude nighttime conditions due to the lack of a comprehensive set of ${ }^{\circ} \mathrm{NO}_{3}$ rate constants and yields (cf Section 2). The model is initialized with 21 PAHs at environmentally relevant 
concentrations (Table 1). PAH concentrations decrease over the course of the simulations due to oxidative loss. Of the 21 PAHs, 15 are known or are predicted to form oxy-PAH products commonly reported in fog, cloud, gas or aerosol samples. Initial concentrations of oxy-PAHs are zero and increase as a function of loss of the 15 PAHs. The model does not include PAH loss by dry or wet deposition.

An aqueous phase volume ratio $\left(\phi^{\mathrm{aq}}\right)$ of $3 \times 10^{-7}$ is used and is equivalent to a liquid water content (LWC) of $0.3 \mathrm{~g} \mathrm{~m}^{-3}$, consistent with observations of dense fogs and clouds (Raja et al., 2008; Ervens et al., 2013). A liquid-organic phase volume ratio $\left(\phi^{\text {org }}\right)$ of $3 \times 10^{-12}$ is calculated with Eq. S1-1 and corresponds to $5 \mathrm{mgC} \mathrm{L}^{-1}$ water-insoluble organic carbon (OC; assuming a liquid organic phase density of $0.7 \mathrm{~g} \mathrm{~cm}^{-3}$ which is $70 \% \mathrm{C}$ by mass, i.e., a ratio of organic matter to organic carbon $(\mathrm{OM} / \mathrm{OC})$ of 1.4$)$. This ratio is in agreement with the average of OM/OC ratios $(1.3$ - 1.5) that were observed for water-insoluble organic matter (Turpin and Lim, 2001). For 305 more oxygenated, water-soluble compounds the ratio might be much higher; however, such compounds are likely not present in a separate organic phase but will be mixed with the aqueous phase. These phase volume ratios are comparable to the liquid water and particle volume ratios employed by Lei and Wania (2004) $\left(\phi^{\mathrm{aq}}=3 \times 10^{-7}\right.$ and $\phi^{\mathrm{PM}}=1 \times 10^{-12}$ respectively) in a model to describe PAH processing in clouds. It is obvious that our set of conditions in terms of LWC, 310 drop sizes and initial concentrations of PAHs and oxidants only reflects a very limited view of the complex three-phase-system as encountered in atmospheric fogs. However, the aim of our study is not to map out the full parameter space but to explore whether under typical fog conditions PAHs can be efficiently processed in the aqueous phase. Therefore, our study should give an idea whether kinetic data of PAHs should be further investigated in order to yield a more 315 comprehensive data set in order to explore a possibly neglected but important PAH sink. 
Our study neglects chemical reactions on the interstitial particles of clouds and fogs. These particles comprise a surface area and volume being several orders of magnitude smaller than the droplet phase. Given that heterogeneous processes on particles are usually considered too slow to compete with gas phase processes (Atkinson and Arey, 1994, Zimmermann et al., 2013), it can be expected that in clouds/fogs their role is even smaller since only small and hydrophobic particles are not activated into cloud droplets.

To estimate surface coverage of cloud/fog droplets, the dimensionless liquid organic surface film coverage $\theta^{\text {org }}$ is calculated in the present work (Eq. 6) from the cross-sectional area of an alkyl chain, $A^{\text {org }}\left[\mathrm{m}^{2} \mathrm{~m}_{\text {air }}^{-3}\right]$, and the total fog droplet surface area, $A^{\text {fog }}\left[\mathrm{m}^{2} \mathrm{~m}_{\text {air }}^{-3}\right]$.

Eqs. (S2-1) - (S2-4) (Appendix 2, Supplemental Material) are used to calculate $A^{\text {org }}$ and $A^{\text {fog }}$ finding that only a small fraction of the simulated fog droplets is covered by an organic phase. Very high enrichment factors of PAHs in the aqueous phase have been reported in fogs with relatively low LWC $\left(<0.05 \mathrm{~g} \mathrm{~m}^{-3}\right.$ ) (Glotfelty et al., 1990). However, this study did not specify the geometry of the phase, i.e., whether droplets were completely covered by an organic surface film. It can be expected that surface coverage is even reduced for clouds/fogs with higher LWC as considered in the present study.

Table 1. Initialization of the Box Model

\begin{tabular}{lcl}
\hline Parameter & Abbreviation / Symbol & Initial Values \\
\hline Phase volumes & & \\
\hline $\begin{array}{l}\text { aqueous phase volume ratio } \\
\begin{array}{l}\text { liquid-organic phase } \\
\text { volume ratio }\end{array}\end{array}$ & $\phi^{\text {aq }}$ & $3 \times 10^{-7} \mathrm{vol} / \mathrm{vol}$ \\
\hline Oxidants (constant) & $\phi^{\text {org }}$ & $3 \times 10^{-12} \mathrm{vol} / \mathrm{vol}$ \\
\hline Hydroxyl radical & & \\
\hline
\end{tabular}




\begin{tabular}{|c|c|c|}
\hline $\begin{array}{l}\text { Ozone } \\
\text { Atomic oxygen }\end{array}$ & $\begin{array}{c}\mathrm{O}_{3} \\
\mathrm{O}\left({ }^{3} \mathrm{P}\right) \\
\end{array}$ & $\begin{array}{l}30 \mathrm{ppb} \\
200 \text { molecules } \mathrm{cm}^{-3}\end{array}$ \\
\hline \multicolumn{3}{|l|}{ PAHs } \\
\hline Naphthalene & NAP & $100(20-500) \mathrm{ng} \mathrm{m}^{-3}$ \\
\hline Acenaphthylene & $\mathrm{ACY}$ & $4.1(1-17) \mathrm{ng} \mathrm{m}^{-3}$ \\
\hline Acenaphthene & $\mathrm{ACE}$ & $4.1(1-17) \mathrm{ng} \mathrm{m}^{-3}$ \\
\hline $9 H$-Fluorene & FLU & $8.7(3-25) \mathrm{ng} \mathrm{m}^{-3}$ \\
\hline Phenanthrene & PHE & $13(7-23) \mathrm{ng} \mathrm{m}^{-3}$ \\
\hline Anthracene & ANT & $0.5(0.1-2.5) \mathrm{ng} \mathrm{m}^{-3}$ \\
\hline Fluoranthene & FLT & $0.4(0.09-2) \mathrm{ng} \mathrm{m}^{-3}$ \\
\hline Pyrene & PYR & $2.3(0.4-13) \mathrm{ng} \mathrm{m}^{-3}$ \\
\hline Acephenanthrylene & $\mathrm{ACP}$ & $0.4(0.09-2) \mathrm{ng} \mathrm{m}^{-3}$ \\
\hline $11 H$-Benzo[a]fluorene & BAU & $0.06(0.01-0.4) \mathrm{ng} \mathrm{m}^{-3}$ \\
\hline $11 H$-Benzo $[b]$ fluorene & $\mathrm{BBU}$ & $0.06(0.01-0.4) \mathrm{ng} \mathrm{m}^{-3}$ \\
\hline Benzo $[a]$ anthracene & BAA & $0.12(0.04-0.35) \mathrm{ng} \mathrm{m}^{-3}$ \\
\hline Chrysene & $\mathrm{CHY}$ & $0.23(0.13-0.42) \mathrm{ng} \mathrm{m}^{-3}$ \\
\hline Retene & RET & $0.08(0.02-0.35) \mathrm{ng} \mathrm{m}^{-3}$ \\
\hline Benzo $[b]$ fluoranthene & $\mathrm{BBF}$ & $0.04(0.012-0.16) \mathrm{ng} \mathrm{m}^{-3}$ \\
\hline Benzo $[k]$ fluoranthene & BKF & $0.03(0.006-0.1) \mathrm{ng} \mathrm{m}^{-3}$ \\
\hline Benzo $[a]$ pyrene & BAP & $0.04(0.01-0.2) \mathrm{ng} \mathrm{m}^{-3}$ \\
\hline Benzo[e]pyrene & $\mathrm{BEP}$ & $0.03(0.003-0.26) \mathrm{ng} \mathrm{m}^{-3}$ \\
\hline Indeno[1,2,3-cd]pyrene & IND & $0.05(0.013-0.2) \mathrm{ng} \mathrm{m}^{-3}$ \\
\hline Dibenz $[a, h]$ anthracene & DBA & $0.01(0.002-0.1) \mathrm{ng} \mathrm{m}^{-3}$ \\
\hline Benzo $[g, h, i]$ perylene & BGP & $0.08(0.02-0.32) \mathrm{ng} \mathrm{m}^{-3}$ \\
\hline
\end{tabular}

Notes: PAH concentrations are an overview from the literature of the totals of all three phases and are representative of total PAH levels (gas + particulate) in urban areas; ranges are in parenthesis (Eiguren-Fernandez et al., 2004; Albinet et al., 2007; Delgado-Saborit et al., 2013). The concentrations of all oxidants are held constant. 


\section{Model Results and Discussion}

PAHs with two to four rings such as NAP and $\mathrm{CHY}$ are predicted to be primarily in the gas phase $\left(x^{\mathrm{g}}>0.93\right)$ at $25^{\circ} \mathrm{C}$ while DBA (five rings), IND (six rings), and BGP (six rings) are predicted to have a significant fraction in droplets $\left(x^{\mathrm{g}}<0.11\right)$ with aqueous phase fractions $x^{\mathrm{aq}}$ of 0.02 to 0.05 and liquid organic phase fractions of $0.85 \leq x^{\text {org }} \leq 0.91$ (Figs. 2 and S4).

All monocarbonyl oxy-PAHs are predicted to be predominantly in the gas phase $\left(x^{\mathrm{g}}>\right.$ $0.82)$ while the dicarbonyl oxy-PAHs are principally in droplets $\left(x^{\mathrm{g}}<0.32 ; 0.32 \leq x^{\mathrm{aq}} \leq 0.97 ; 0<\right.$ $\left.x^{\text {org }} \leq 0.68\right)$ with the exception of oANT $\left(x^{\mathrm{g}}=0.76\right)$. The oxy-PAH with the greatest $x^{\mathrm{aq}}$ is the dicarbonyl oPHE2 with $x^{\mathrm{aq}}=0.97$. The PAHs are predicted to be mostly absent from the aqueous phase with the five-ring PAH BBF having the greatest $x^{\mathrm{aq}}\left(x^{\mathrm{aq}}(\mathrm{BBF})=0.06\right)$.

As oxy-PAHs are less hydrophobic than PAHs, many of the oxy-PAHs are predicted to partition into the aqueous phase more efficiently than their PAH counterparts: non-carbonyls (i.e., PAH) have $x^{\mathrm{aq}}<0.07$, the monocarbonyl oxy-PAH $x^{\mathrm{aq}}$ range from 0.002 to 0.11 , and the dicarbonyl oxy-PAH $x^{\mathrm{aq}}$ range from 0.24 to 0.97 . This difference is expected since the presence of oxygen atoms in oxy-PAHs increases intermolecular attractions and water solubility, as evidenced by the smaller PAH $K_{\mathrm{OW}}$ (Table S1). The dicarbonyl oxy-PAHs are predicted to have greater aqueous phase fractions than monocarbonyl oxy-PAHs (ranging from 0.24 to 0.97 and 0.002 to 0.11, respectively; Fig. 2). The number of rings in PAHs and oxy-PAHs has less of an effect on $x^{\mathrm{aq}}$ than the number of carbonyl groups; for example, $x^{\mathrm{aq}}(\mathrm{NAP})=2 \times 10^{-5}$ (two-ring non- 


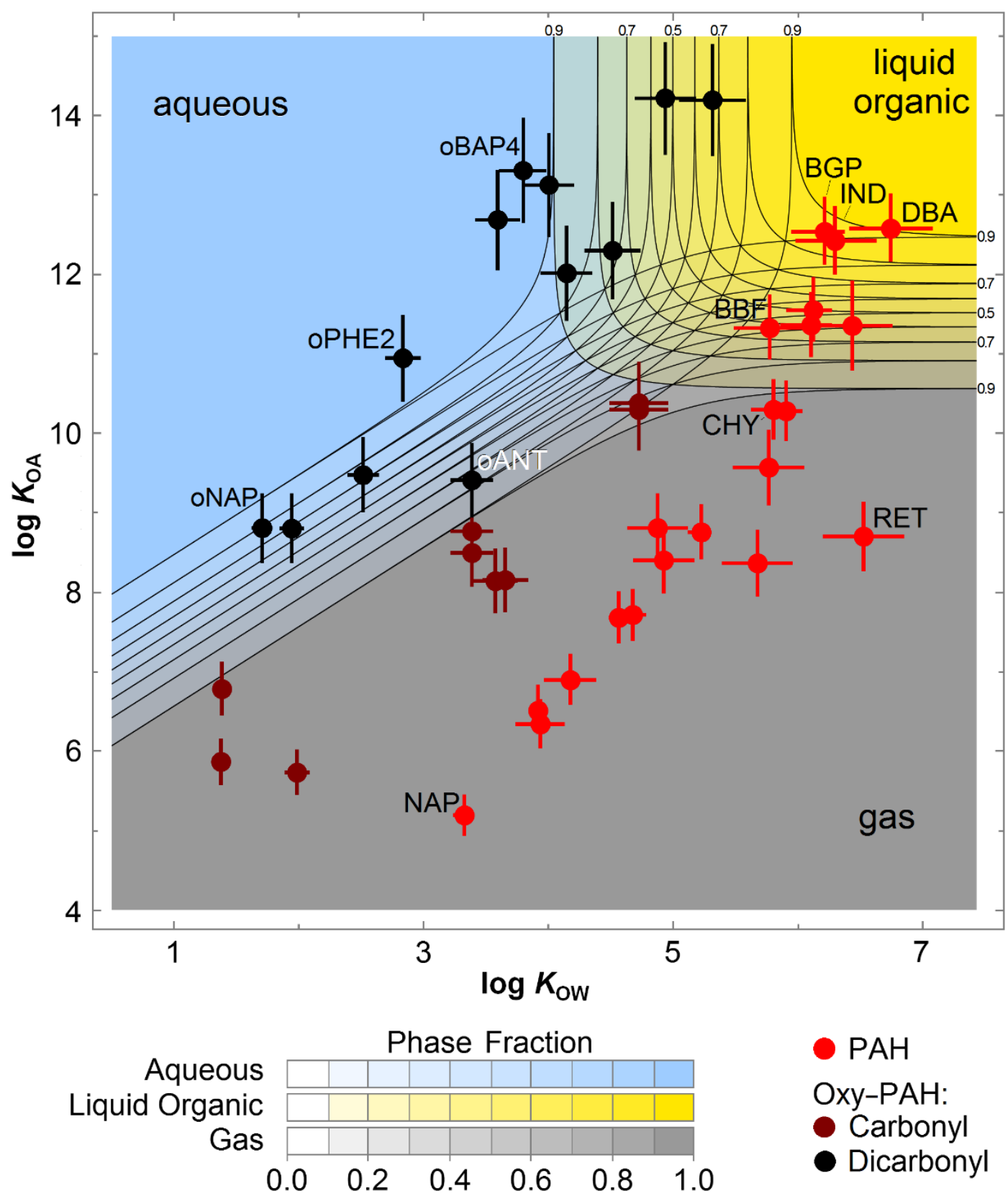

Fig. 2. Predicted PAH and oxy-PAH phase fractions at $25^{\circ} \mathrm{C}$. The calculated fractiof 65 in the aqueous, liquid organic, and gas phases are in blue, yellow, and greyscale respectively, with PAH (red circles), monocarbonyl oxy-PAHs (dark-red circles), and dicarbonyl oxy-PAHs (black circles). Phase fraction lines are labeled above and to the right of the plot for clarity. Error bars show literature-reported error (95\% CI, Odabasi et al., 2006) or 5\% if an error is not reported. See Fig. S4 for labels of all PAHs and oxy4.2 PAHs. 


\section{Comparison with partitioning as reported in the literature}

To the best of the authors' knowledge, the only field study of PAH and/or oxy-PAH fractionation between the gas and fog droplet phases is Ehrenhauser et al. (2012). They demonstrated the temperature dependence of observed aqueous/gas partitioning from literature $H$ at $25^{\circ} \mathrm{C}$ for PHE, ANT, PYR, ACE, FLU, and BAP. These PAHs have greater $x^{\text {fog }}$ (the sum of $x^{\text {aq }}$ and $x^{\text {org }}$ ) at 2 to $7^{\circ} \mathrm{C}$ than the $x^{\text {fog }}$ in a pure water / gas system at $25^{\circ} \mathrm{C}$. The model in the current work predicts $x^{\text {fog }}=0.55$ for BAP and $x^{\text {fog }}<0.01$ for PHE, ANT, PYR, ACE, and FLU at

$37525^{\circ} \mathrm{C}$ (Fig. 2). The presence of organic compounds in droplets and temperature influence $x^{\text {fog }}$ (Sections 4.4.1 and 4.4.2, respectively).

In the absence of fogs and clouds, PAHs and oxy-PAHs partition only between the gas and particulate phases (Eiguren-Fernandez et al., 2004; Alam et al., 2013). If the particles are exposed to conditions of relative humidity $(\mathrm{RH})<100 \%$, the water volume is reduced by several 380 orders of magnitude $\left(\sim 10 \mu \mathrm{g} \mathrm{m}^{-3}\right.$ vs. $\left.0.3 \mathrm{~g} \mathrm{~m}^{-3}\right)$ Under those conditions the partitioning of PAHs in the gas and liquid organic phases is predicted to be nearly the same as when fogs or clouds are present ( $<2 \%$ difference for BBF; compare PAHs in Figs. 2 and S5). At RH $<100 \%$, there is as much PAH in the particulate phase as it is predicted for $x^{\mathrm{org}}+x^{\mathrm{aq}}$ in the three-phase system since $x^{\text {org }}$ increases and $x^{\mathrm{aq}} \sim 0$ whereas $x^{\mathrm{g}}$ remains approximately the same. However, under those 385 conditions, for some oxy-PAHs (especially the two- and three-ring dicarbonyls), $x^{\mathrm{g}}$ increases if $\mathrm{RH}<100 \%\left(\right.$ e.g., oNAP $x^{\mathrm{g}}=0.21$ and $x^{\mathrm{g}}>0.99$ in Figs. 2 (in the presence of fog) and S5 (RH $<$ $100 \%)$, respectively).

\subsection{Chemical removal of PAHs and formation of oxy-PAHs}


In order to compare chemical loss rates in each phase, the gas phase rate constants $k(\mathrm{~g})$ 390 are multiplied by the oxidant concentrations to obtain pseudo-first order loss rates $k^{\prime}(\mathrm{g})\left[\mathrm{s}^{-1}\right]$. Of the processes for which rate constants are available, $k^{\prime}\left(\mathrm{O}\left({ }^{3} \mathrm{P}\right), \mathrm{g}\right)$ are three to five orders of magnitude smaller than $k^{\prime}\left({ }^{\circ} \mathrm{OH}, \mathrm{g}\right)$ and $k^{\prime}\left(\mathrm{O}_{3}, \mathrm{~g}\right)$ as seen in Fig. 3A. The $k^{\prime}\left(\mathrm{O}_{3}, \mathrm{~g}\right)$ are smaller by three orders of magnitude than $k^{\prime}\left({ }^{\circ} \mathrm{OH}, \mathrm{g}\right)$ except for $\mathrm{ACY}$, which is likely due to the ease of $\mathrm{O}_{3}$ reacting with the double bond in the five-membered ring of ACY (Calvert et al., 2002). PAH 395 lifetimes are calculated using:

$\tau[\mathrm{s}]=\frac{1}{\sum\left(k^{\prime}\right)}$

At $25^{\circ} \mathrm{C}$, chemical lifetimes in fogs and clouds $\tau_{r x n}^{\text {fog }}$ are 0.5 to 7.2 hours (Table 2). This is shorter than or comparable to lifetimes due to chemical loss in the absence of an aqueous phase: the chemical lifetime in the gas and particulate phases $\tau_{r x n}^{\mathrm{g}, \mathrm{PM}}$ is estimated to range from 1 to 300 400 hours (Table 2; Keyte et al., 2013). $\tau_{r x n}^{\text {fog }}$ is also shorter than physical loss processes: the lifetime of PAHs due to dry deposition $\tau_{\text {drydep }}$ is estimated to be 1 to 14 days and due to wet deposition $\tau_{\text {wetdep }}$ is 5 to 15 months (Bidleman, 1988; Škrdlíková et al., 2011). The typical lifetime of aerosol particles in the atmosphere, $\tau_{d e p}^{\mathrm{PM}}$, is generally estimated as about one week.

To determine the importance of the different reactions for each $\mathrm{PAH}$, the loss fluxes 405 (rates of disappearance), $v_{\mathrm{PAH}}\left[\mathrm{M} \mathrm{s}^{-1}\right]$ are calculated with Eqs. (8) - (10) and compared in Fig. 3B:

$v_{\mathrm{PAH}(\mathrm{g}), \mathrm{oxidant}(\mathrm{g})}=k[\mathrm{PAH}]_{\mathrm{g}}[\text { oxidant }]_{\mathrm{g}}$

$v_{\mathrm{PAH}(\mathrm{aq})}=k[\mathrm{PAH}]_{\mathrm{aq}}$

$v_{\mathrm{PAH}(\mathrm{org})}=k[\mathrm{PAH}]_{\mathrm{org}}$

The fluxes of ${ }^{\circ} \mathrm{OH}(\mathrm{g})$ reactions are the largest of all phases for two-, three-, and four-ring 410 PAHs since they are primarily gas phase $\left(x^{\mathrm{g}}>0.92\right)$ at $25^{\circ} \mathrm{C}$. The $v_{\mathrm{PAH}, \cdot \mathrm{OH}}$ of $\mathrm{BBF}, \mathrm{BBK}, \mathrm{BAP}$, 
and BEP are of the same order of magnitude as $v_{\mathrm{PAH}(\text { org) }}$ since their $x^{\mathrm{g}}$ are close to $0.5\left(0.46 \leq x^{\mathrm{g}} \leq\right.$ $0.59)$ at $25^{\circ} \mathrm{C}$. For IND, DBA, and BGP, $v_{\mathrm{PAH}(\mathrm{org})}>v_{\mathrm{PAH}(\mathrm{g})}$ due to their low gas phase fractions $\left(0.08 \leq x^{\mathrm{g}} \leq 0.10\right)$ and their greater organic phase fractions $\left(0.85 \leq x^{\mathrm{org}} \leq 0.91\right.$; Table 2 and Fig. 3B). For ANT, PYR, BAA, and BAP the $k(\mathrm{aq})>k^{\prime}\left({ }^{\circ} \mathrm{OH}, \mathrm{g}\right)$ while the volume-weighted rates $415 v_{\mathrm{PAH}(\mathrm{aq})}<v_{\mathrm{PAH},{ }_{\mathrm{OH}}}$ since $x^{\mathrm{aq}}<x^{\mathrm{g}}$ for these PAHs $\left(0.0003 \leq x^{\mathrm{aq}} \leq 0.04\right.$ and $\left.0.46 \leq x^{\mathrm{g}} \leq 0.99\right)$. 


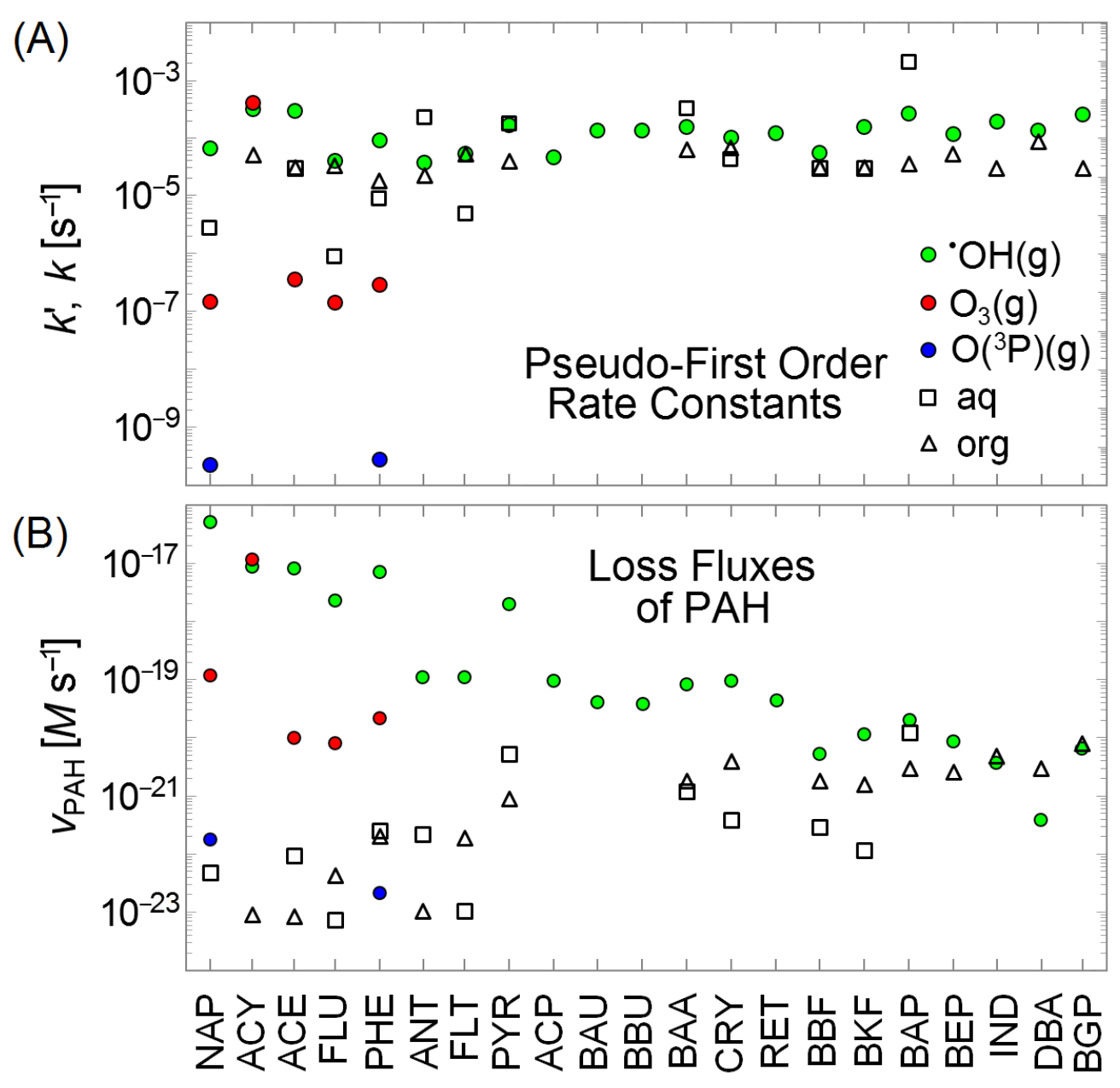

Fig. 3. A comparison of pseudo-first order rate constants (A) and rates of PAH disappearance (B) at $25^{\circ} \mathrm{C}$. The gas phase oxidants in the model are the hydroxyl radical $\left({ }^{\circ} \mathrm{OH}\right)$, ozone $\left(\mathrm{O}_{3}\right)$, and atomic oxygen $\left(\mathrm{O}\left({ }^{3} \mathrm{P}\right)\right)$; aq and org are the photooxidation in the aqueous and liquid organic phases, respectively. See Table 1 for PAH abbreviations. 
The concentrations of oxy-PAH products are influenced by $x^{\mathrm{aq}}, x^{\mathrm{org}}, x^{\mathrm{g}}, k^{\prime}(\mathrm{g}), k(\mathrm{aq})$, $420 k($ org $)$, and $Y_{\mathrm{m}}$ as well as the chemical loss processes of oxy-PAHs. After three hours, $46 \%$ of the initial carbon mass in PAHs is predicted to remain as carbon in PAHs and $0.73 \%$ as carbon in oxy-PAHs. The other $53 \%$ of the original carbon mass is not speciated in this work but likely includes monocyclic aromatics and non-aromatic organic compounds (Moza et al., 1999; Mallakin et al., 2000; Kong and Ferry, 2003; Woo et al., 2009).

\subsection{Discussion of uncertainties in predicted partitioning ratios for atmospheric conditions}

\subsubsection{The influence of salts and co-solvents}

It is known that small-molecule organic co-solvents (e.g., methanol, ethanol, and propanol) can enhance PAH solubility (Fan and Jafvert, 1997; Yap et al., 2012). In very polluted fog or in water associated with deliquesced aerosol particles (i.e., relatively low LWC), high

430 concentrations of dissolved salts and organics can cause deviations from Henry's law. The salt effects on solubility are generally smaller than temperature effects over atmospherically relevant ranges. For example, Whitehouse (1984) reported 1 to $15 \%$ salting out of PHE, ANT, and BAP for a salinity increase from 0 to $4 \%$ and a $24 \%$ salting-in effect for BAA over the same salinities; however, there is a 50 to $70 \%$ decrease in solubility when temperature decreases from 25 to $8^{\circ} \mathrm{C}$.

435 Typically, fog water salinity is about two orders of magnitude lower (0.07\%o; Collett et al., 2008) than applied in the previous study. Shahpoury et al. (2015) found that ionic compounds have little impact on the scavenging of PAHs by rain when the salinity in rain increases from approximately 0.002 to $0.03 \%$. Therefore, under typical conditions as encountered in clouds and fogs, it can be expected that 'salting in' or 'salting out' effects are minor. 


\subsubsection{Influence of temperature on partitioning}

The temperature applied in our model is $25^{\circ} \mathrm{C}$, while typical fog and cloud observations in range from $0^{\circ} \mathrm{C}$ to $19^{\circ} \mathrm{C}$ (Capel et al., 1990; Erel et al., 1993; Herckes et al., 2002; ReyesRodríguez, et al., 2009; Ervens et al., 2013). The use of $25^{\circ} \mathrm{C}$ is constrained by the availability of partitioning ratios and rate constants at this temperature. Very few temperature-dependent $K_{\mathrm{OW}}$ partitioning ratios and kinetic rate constants have been published for PAHs and oxy-PAHs (Frerichs et al., 1990; Lei et al., 2000). Temperature-dependent $K_{\mathrm{OA}}$ partitioning ratios exist for half of the PAHs and oxy-PAHs (23 out of 46) (Harner and Bidleman, 1998; Odabasi et al., 2006; Parnis et al., 2015).

As temperature increases, the vapor pressure increase is generally greater than the solubility increase in both water and liquid organic, which results in smaller $H^{*}$ and $K_{\mathrm{OA}}$. The increase in water solubility $\left(H^{*}\right)$ is greater than the solubility increase in 1 -octanol $\left(K_{\mathrm{OA}}\right)$ which results in smaller $K_{\mathrm{OW}}$ as temperature increases (Eq. 4). Therefore, $K_{\mathrm{OA}}, K_{\mathrm{OW}}$, and $H^{*}$ all decrease with increasing temperature whereas $H^{*}$ has generally the strongest temperature dependence. The change in BAA's $K_{\mathrm{OA}}$ and $K_{\mathrm{OW}}$ is seen in Fig. S6A resulting in higher $x^{\mathrm{g}}$ at $25^{\circ} \mathrm{C}$ than at $1{ }^{\circ} \mathrm{C}\left(x^{\mathrm{g}}=0.94\right.$ and $x^{\mathrm{g}} \sim 0.4$ respectively). BAA is the only PAH of this study with temperature-dependent $K_{\mathrm{OA}}$ and $K_{\mathrm{OW}}$ partitioning ratios available (Lei et al., 2000; Odabasi et al., 2006). Assuming other PAHs have similar temperature dependencies, the $x^{\mathrm{g}}$ at $25^{\circ} \mathrm{C}$ are 0.2 to 0.6 greater than $x^{\mathrm{g}}$ at $1^{\circ} \mathrm{C}$ (Fig. S6B) for PAHs whose $K_{\mathrm{OA}}$ are near the gas phase / liquid organic 460 phase boundary at $25^{\circ} \mathrm{C}$ (i.e., $\left.\sim 10 \leq \log K_{\mathrm{OA}} \leq 12\right)$, including BAA, CHY, BBF, BKF, BAP, and BEP. Extrapolation of the oxy-PAH $K_{\mathrm{OA}}, K_{\mathrm{OW}}$, and $x^{\mathrm{g}}$ changes as a function of temperature are not attempted in Fig. S6B since oxy-PAHs have additional (and stronger) intermolecular 
interactions than PAHs, such as hydrogen bonding and dipole - dipole interactions and therefore likely have different temperature dependencies.

Our model calculations likely overestimate $x^{\mathrm{g}}$ for some PAHs in the presence of fogs and clouds as temperatures are typically lower than $25^{\circ} \mathrm{C}$; therefore, under typical cloud/fog conditions, the condensed phases may represent an even larger sink for PAHs than as demonstrated in Fig. 3B.

\subsection{Organic film coverage of the air/water interface}

The geometry of the organic phase is not specified in the present model other than each phase is in contact with the other two, i.e., no complete organic film exists on the drop surface (Fig. 1). Many researchers have concluded that PAHs adsorb to water surfaces as hydrophobic surface layers (Moza et al., 1999; Valsaraj, 2004; Chen et al., 2006; Raja and Valsaraj, 2006; Kahan and Donaldson, 2007; Chen et al., 2011; Styler et al., 2011). Gill et al. (1983) estimated it would require $300 \mathrm{mg} \mathrm{L}^{-1}$ organic matter for the entire surface of fog drops with diameters 1 to $10 \mu \mathrm{m}$ to be coated with an organic monolayer film. Depending on the compound, this equates to 180 to $250 \mathrm{mgC} \mathrm{L}^{-1}$ which is greater than the TOC reported in typical fog and clouds $(0.1$ to 40 mgC L ${ }^{-1}$; Erel et al., 1993; Herckes et al., 2002; Raja et al., 2008; Reyes-Rodríguez, et al., 2009; Ehrenhauser et al., 2012; Ervens et al., 2013; Herckes et al., 2013). It should be noted that generally only less than $\sim 15 \%$ of TOC is insoluble, i.e. might contribute to a separate organic phase in/on fog droplets (Herckes et al., 2015).

Using Eq. 6 to estimate surface coverage of cloud/fog droplets yields $\theta^{\text {org }}<1.3 \%$. Even if all the TOC (5 mgC L $\left.{ }^{-1}\right)$ was completely water immiscible and had the molecular dimensions of 
485 1-octanol, the droplet surface coverage will be less than $1.3 \%$ for $10 \mu \mathrm{m}$ droplets (Eqs. (6) and (S2-1) - (S2-4) in Appendix 2, Supplemental Material). Thus, under all circumstances, the surface of a typical fog or cloud droplet is too large to be wholly covered with an organic monolayer. Therefore, our concept of all three phases being in contact with each other is valid.

\subsubsection{Heterogeneous surface reactions}

Heterogeneous reactions of PAHs adsorbed at the air / water interface have been reported for several PAHs (Valsaraj, 2004; Chen et al., 2006; Raja and Valsaraj, 2006; Kahan and Donaldson, 2007; Donaldson and Valsaraj, 2010; Styler et al., 2011). However, the present work does not include heterogeneous PAH reactions at the air / water interface since the area for heterogeneous surface reactions will be small as compared to volume reactions in the aqueous or organic phases, respectively, due to the relatively small surface-to-volume ratio of droplets as compared to (wet) particles.

This work further does not include heterogeneous reactions of PAHs adsorbed at a water / solid interface, such as what might occur at the surface of a hygroscopic sub-micrometer particle entrained in the interior of a droplet. A comparison of CHY kinetic rate constants measured in water with those measured in a suspension of smectite clay in water reveals little difference: Kong and Ferry (2003) reported $k($ aq-smectite $)=4.3 \times 10^{-5} \mathrm{~s}^{-1}$ while Zepp and Schlotzhauer (1979) reported $k(\mathrm{aq})=4.4 \times 10^{-5} \mathrm{~s}^{-1}$ and Fasnacht and Blough (2002) reported $k(\mathrm{aq})=9 \times 10^{-5} \mathrm{~s}^{-}$

1. These are of similar magnitude as $k(\mathrm{org})=6.8 \times 10^{-5} \mathrm{~s}^{-1}$ (Plata et al., 2008), $k($ aq- $10 \%$ methanol $)=1.4 \times 10^{-5} \mathrm{~s}^{-1}$ (Kong and Ferry, 2003), and less than an order of magnitude smaller 505 than CHY $k^{\prime}\left({ }^{\circ} \mathrm{OH}, \mathrm{g}\right)=1.0 \times 10^{-4} \mathrm{~s}^{-1}$ (Calvert et al., 2002 with $\left[{ }^{\circ} \mathrm{OH}\right]=3 \times 10^{6}$ molecules $\mathrm{cm}^{-3}$ ) 
and therefore are not expected to substantially contribute to PAH loss in the atmospheric multiphase system.

\section{Summary}

The phase distribution of PAHs and oxy-PAHs is predicted using a multiphase box model that includes gas, aqueous and organic liquid phases that are in contact with each other since the surface of typical fog and cloud droplets $\left(d=10 \mu \mathrm{m}\right.$, TOC $\left.<50 \mathrm{mgC} \mathrm{L}^{-1}\right)$ is predicted to be too large to be completely covered by a liquid organic surface film. At $25^{\circ} \mathrm{C}$, PAHs with two, three and four rings are predicted to be primarily in the gas phase $\left(x^{\mathrm{g}}>0.92\right)$ while five- and six-ring PAHs partition significantly into droplets $\left(x^{\mathrm{fog}}=\left(x^{\mathrm{aq}}+x^{\mathrm{org}}\right)>0.40\right.$ with $x^{\text {org }}$ having usually the larger fraction with $\left.0.37<x^{\text {org }}<0.91\right)$. At lower temperatures, such as those typical of fogs and clouds, $x^{\text {fog }}$ is expected to be 0.2 to 0.6 higher for several four- and five-ring PAHs.

The most sensitive parameters are the temperature dependencies of $K_{\mathrm{OA}}$ values. Many values in this study are estimated from the EPISuite and/or are reported only at $25^{\circ} \mathrm{C}$. As an example, BAA is expected have $x^{\mathrm{g}}=0.94$ at $25^{\circ} \mathrm{C}$ and $x^{\mathrm{g}} \sim 0.4$ at $1^{\circ} \mathrm{C}$. Additionally, liquidorganic and aqueous-phase photooxidation rate constants are unavailable for many of the PAHs and most of the oxy-PAHs.

The oxidation of PAHs in the multiphase system is predicted to result in significantly shorter lifetimes ( $<8$ hours) than dry and wet deposition processes $(1-14$ days, $5-15$ months, respectively) and shorter or comparable lifetimes of PAHs relative to oxidation in the gas / organic system (1 to 300 hours). At $25^{\circ} \mathrm{C}$, gas-phase ${ }^{\circ} \mathrm{OH}$ is the predicted to be an important but not always dominant oxidant for the removal of PAHs. The loss fluxes due to ${ }^{\circ} \mathrm{OH}$ reaction in the gas phase of BBF, BKF, BAP, BEP are on the same order of magnitude as losses in the liquid 
organic phase; for IND, DBA, BGP those in the organic phase even exceed those in the gas phase. Our analysis shows that even though PAHs are not very water-soluble, the condensed

530 phase in fog and clouds (i.e., the droplets) cannot be neglected as a PAH sink, in particular at low temperatures.

\section{Acknowledgements}

This work was supported in part by the U.S. National Science Foundation [grant numbers AGS0907261, AGS0847710], as well as the NOAA's Climate Goal. 


\section{References}

Alaee, M., Whittal, R.M., Strachan, W.M.J., 1996. The Effect of Water Temperature and Composition on Henry's Law Constant for Various PAH's. Chemosphere 32, 1153-1164. http://doi:10.1016/0045-6535(96)00031-8.

540 Alam, M.S., Delgado-Saborit, J.M., Stark, C., Harrison, R.M., 2013. Using Atmospheric Measurements of PAH and Quinone Compounds at Roadside and Urban Background Sites to Assess Sources and Reactivity. Atmospheric Environment 77, 24-35. doi:10.1016/j.atmosenv.2013.04.068.

Albinet, A., Leoz-Garziandia, E., Budzinski, H., ViIlenave, E., 2007. Polycyclic Aromatic Hydrocarbons (PAHs), Nitrated PAHs and Oxygenated PAHs in Ambient Air of the Marseilles Area (South of France): Concentrations and Sources. Science of the Total Environment 384, 280-292. http://doi:10.1016/j.scitotenv.2007.04.028.

Atkinson, R. and J. Arey, 1994, Atmospheric chemistry of gas-phase polycyclic aromatic hydrocarbons: formation of atmospheric mutagens, Environmental Health Perspectives, 102, Suppl. 4, 117-126, http://www.ncbi.nlm.nih.gov/pmc/articles/PMC1566940/

Bamford, H.A., Poster, Di.L., Baker, J.E., 1999. Temperature Dependence of Henry's Law Constants of Thirteen Polycyclic Aromatic Hydrocarbons Between $4{ }^{\circ} \mathrm{C}$ and $31^{\circ} \mathrm{C}$. Environmental Toxicology and Chemistry 18, 1905-1912. http://doi:10.1002/etc.5620180906.

Bedjanian, Y. and M. L. Nguyen, 2010, Kinetics of the reactions of soot surface-bound polycyclic aromatic hydrocarbons with O3, Chemosphere, 79, 4, 387-393, http://dx.doi.org/10.1016/j.chemosphere.2010.02.009

Bidleman, T.F., 1988. Atmospheric Processes - Wet and Dry Deposition of Organic Compounds are Controlled by Their Vapor-Particle Partitioning. Environmental Science and Technology 22, 361-367. http://doi:10.1021/es00169a002.

560 Calvert, J.G., Atkinson, R., Becker, K.H., Kamens, R.M., Seinfeld, J.H., Wallington, T.H., Yarwood, G., 2002. The Mechanisms of Atmospheric Oxidation of the Aromatic Hydrocarbons. Oxford University Press. New York, New York, 134-195.

Capel, P.D., Gunde, R., Zuercher, F., Giger, W., 1990. Carbon Speciation and Surface Tension of Fog. Environmental Science and Technology 24, 722-727. http://doi:10.1021/es00075a017.

565 Capel, P.D., Leuenberger, C., Giger, W., 1991. Hydrophobic Organic Chemicals in Urban Fog. Atmospheric Environment Part A. General Topics 25, 1335-1346. http://doi:10.1016/09601686(91)90244-2.

Chen, J., Ehrenhauser, F.S., Valsaraj, K.T., Wornat, M.J., 2006. Uptake and UV-Photooxidation of Gas-Phase PAHs on the Surface of Atmospheric Water Films. 1. Naphthalene. Journal of Physical Chemistry A 110, 9161-9168. http://doi:10.1021/jp062560b.

Chen, J., Ehrenhauser, F.S., Liyana-Arachchi, T.P., Hung, F.R., Wornat, M.J., Valsaraj, K.T., 2011. Adsorption of Gas-Phase Phenanthrene on Atmospheric Water and Ice Films. Polycyclic Aromatic Compounds 31, 201-226. http://doi:10.1080/10406638.2011.585370. 
Clark, C.D., De Bruyn, W.J., Ting, J., Scholle, W., 2007. Solution Medium Effects on the 575 Photochemical Degradation of Pyrene in Water. Journal of Photochemistry and Photobiology A: Chemistry 186, 342-348. doi:10.1016/j.jphotochem.2006.09.003.

Collett Jr., J.L., Herckes, P., Youngster, S., Lee, T., 2008. Processing of Atmospheric Organic Matter by California Radiation Fogs. Atmospheric Research, Third International Conference on Fog, Fog Collection and Dew 87, 232-241. http://doi:10.1016/j.atmosres.2007.11.005.

580 Delgado-Saborit, J.M., Alam, M.S., Godri Pollitt, K.J., Stark, C., Harrison, R.M., 2013. Analysis of Atmospheric Concentrations of Quinones and Polycyclic Aromatic Hydrocarbons in Vapour and Particulate Phases. Atmospheric Environment 77, 974-982. http://doi:10.1016/j.atmosenv.2013.05.080.

de Maagd, P.G.-J., ten Hulscher, D.T.E.M., van den Heuvel, H., Opperhuizen, A., Sijm, 585 D.T.H.M., 1998. Physicochemical Properties of Polycyclic Aromatic Hydrocarbons: Aqueous Solubilities, N-Octanol/Water Partition Coefficients, and Henry's Law Constants. Environmental Toxicology and Chemistry 17, 251-257. http://doi:10.1002/etc.5620170216.

Donaldson, D.J., Valsaraj, K.T., 2010. Adsorption and Reaction of Trace Gas-Phase Organic Compounds on Atmospheric Water Film Surfaces: A Critical Review. Environmental Science and Technology 44, 865-873. http://doi:10.1021/es902720s.

Ehrenhauser, F.S., Khadapkar, K., Wang, Y., Hutchings, J.W., Delhomme, O., Kommalapati, R.R., Herckes, P., Wornat, M.J., Valsaraj, K.T., 2012. Processing of Atmospheric Polycyclic Aromatic Hydrocarbons by Fog in an Urban Environment. Journal of Environmental Monitoring 14, 2566-2579. http://doi:10.1039/c2em30336a.

595 Eiguren-Fernandez, A., Miguel, A.H., Froines, J.R., Thurairatnam, S., Avol, E.L., 2004. Seasonal and Spatial Variation of Polycyclic Aromatic Hydrocarbons in Vapor-Phase and $\mathrm{PM}_{2.5}$ in Southern California Urban and Rural Communities. Aerosol Science and Technology 38, 447455. http://doi:10.1080/02786820490449511.

EPISuite, 2015. v 4.11 Estimation Programs Interface Suite ${ }^{\mathrm{TM}}$ for Microsoft ${ }^{\circledR}$ Windows. United 600 States Environmental Protection Agency: Washington, DC.

Erel, Y., Pehkonen, S.O., Hoffmann, M.R., 1993. Redox Chemistry of Iron in Fog and Stratus Clouds. Journal of Geophysical Research 98, 18423-18434. http://doi:10.1029/93JD01575.

Ervens, B., Wang, Y., Eagar, J.D., Leaitch, W.R., Macdonald, A.M., Valsaraj, K.T., Herckes, P., 2013. Dissolved Organic Carbon (DOC) and Select Aldehydes in Cloud and Fog Water: The

605 Role of the Aqueous Phase in Impacting Trace Gas Budgets. Atmospheric Chemistry and Physics 13, 5117-5135. http://doi:10.5194/acp-13-5117-2013.

Fan, C., Jafvert, C.T., 1997. Margules Equations Applied to PAH Solubilities in Alcohol-Water Mixtures. Environmental Science and Technology 31, 3516-3522. http://doi:10.1021/es970261h.

Fasnacht, M.P., Blough, N.V., 2002. Aqueous Photodegradation of Polycyclic Aromatic

610 Hydrocarbons. Environmental Science and Technology 36, 4364-4369.

http://doi:10.1021/es025603k. 
Fernández, P., Grimalt, J.O., Vilanova, R.M., 2002. Atmospheric Gas-Particle Partitioning of Polycyclic Aromatic Hydrocarbons in High Mountain Regions of Europe. Environmental Science and Technology 36, 1162-1168. http://doi:10.1021/es010190t.

615 Finlayson-Pitts, Barbara J., and Pitts, Jr., James N. Chemistry of the Upper and Lower Atmosphere: Theory, Experiments, and Applications (1). Burlington, US: Academic Press, 1999.

Fioressi, S., Arce, R., 2005. Photochemical Transformations of Benzo[e]pyrene in Solution and Adsorbed on Silica Gel and Alumina Surfaces. Environmental Science and Technology 39, 3646-3655. http://doi:10.1021/es049192e.

620 Fraser, M.P., Yue, Z.W., Tropp, R.J., Kohl, S.D., Chow, J.C., 2002. Molecular Composition of Organic Fine Particulate Matter in Houston, TX. Atmospheric Environment 36, 5751-5758. http://doi:10.1016/S1352-2310(02)00725-2.

Frerichs, H., Tappe, M., Wagner, H.G., 1990. Comparison of the Reactions of Mono- and Polycyclic Aromatic Hydrocarbons with Oxygen Atoms. Berichte der Bunsengesellschaft für physikalische Chemie 94, 1404-1407. http://doi:10.1002/bbpc.199000043.

Gill, P.S., Graedel, T.E., Weschler, C.J., 1983. Organic Films on Atmospheric Aerosol Particles, Fog Droplets, Cloud Droplets, Raindrops, and Snowflakes. Reviews of Geophysics 21, 903-920. http://doi:10.1029/RG021i004p00903.

Goss, K. 2004. Comment on "Influence of Soot Carbon on the Soil-Air Partitioning of 630 Polycyclic Aromatic Hydrocarbon”. Environmental Science and Technology, 38, 1622-1623. http://doi:10.1021/es0301370

Grossman, J.N., Stern, A.P., Kirich, M.L., Kahan, T.F., 2016. Anthracene and Pyrene Photolysis Kinetics in Aqueous, Organic, and Mixed Aqueous-Organic Phases. Atmospheric Environment 128, 158-164. http://doi:10.1016/j.atmosenv.2015.12.049.

635 Hansch, C., Leo, A., Hoekman, D., 1995. Exploring QSAR Hydrophobic, Electronic, and Steric Constants. American Chemical Society: Washington, DC, pp 348.

Harner, T., Bidleman, T.F., 1998. Measurement of Octanol-Air Partition Coefficients for Polycyclic Aromatic Hydrocarbons and Polychlorinated nNaphthalenes. Journal of Chemical \& Engineering Data 43, 40-46. http://doi:10.1021/je970175x.

640 Harner, T., Mackay, D., 1995. Measurement of Octanol-Air Partition Coefficients for Chlorobenzenes, PCBs, and DDT. Environmental Science and Technology, 29, 1599-1606. http://doi:10.1021/es00006a025

Helmig, D., Harger, W.P., 1994. OH Radical-Initiated Gas-Phase Reaction Products of Phenanthrene. Science of the Total Environment 148, 11-21. http://doi:10.1016/00489697(94)90368-9.

Helmig, D., Arey, J., Atkinson, R., Harger, W.P., McElroy, P.A., 1992. Products of the OH Radical-Initiated Gas-Phase Reaction of Fluorene in the Presence of NOx. Atmospheric Environment 26A, 1735-1745. doi:10.1016/0960-1686(92)90071-R.

Herckes, P., Hannigan, M.P., Trenary, L., Lee, T., Collett Jr., J.L., 2002. Organic Compounds in 650 Radiation Fogs in Davis (California). Atmospheric Research 64, 99-108. http://doi:10.1016/S0169-8095(02)00083-2. 
Herckes, P., Valsaraj, K.T., Collett Jr., J.L., 2013. A Review of Observations of Organic Matter in Fogs and Clouds: Origin, Processing and Fate. Atmospheric Research 122-133, 434-449. http://doi:10.1016/j.atmosres.2013.06.005.

655 Herckes, P., Marcotte, A.R., Wang, Y., Collett Jr., J.L., 2015. Fog Composition in the Central Valley of California Over Three Decades. Atmospheric Research 151, 20-30. http://doi:10.1016/j.atmosres.2014.01.025.

Jang, M., McDow, S.R., 1997. Products of Benz[a]anthracene Photodegradation in the Presence of Known Organic Constituents of Atmospheric Aerosols. Environmental Science and Technology 31, 1046-1053. http://doi:10.1021/es960559s.

Kahan, T.F., Donaldson, D.J., 2007. Photolysis of Polycyclic Aromatic Hydrocarbons on Water and Ice Surfaces. Journal of Physical Chemistry A 111, 1277-1285. http://doi:10.1021/jp066660t.

Keyte, I.J., Harrison, R.M., Lammel, G., 2013. Chemical Reactivity and Long-Range Transport Potential of Polycyclic Aromatic Hydrocarbons - A Review. Chemical Society Reviews 42, 9333-9391. http://doi:10.1039/c3cs60147a.

Koelmans, A. A., M. T. O. Jonker, G. Cornelissen, T. D. Bucheli, P. C. M. VanNoort, O. Gustafsson, 2006, Black carbon: The reverse of its dark side, Chemosphere, 63, 3, 365-377, http://dx.doi.org/10.1016/j.chemosphere.2005.08.034

Kong, L., Ferry, J.L., 2003. Effect of Salinity on the Photolysis of Chrysene Adsorbed to a Smectite Clay. Environmental Science and Technology 37, 4894-4900. http://doi:10.1021/es026124o.

Lammel, G., Sehili, A.M., Bond, T.C., Feichter, J., Grassl, H., 2009. Gas/Particle Partitioning and Global Distribution of Polycyclic Aromatic Hydrocarbons - A Modelling Approach. Chemosphere 76, 98-106. http://doi:10.1016/j.chemosphere.2009.02.017.

Lane, D.A., Fielder, S.S., Townsend, S.J., Bunce, N.J., Zhu, J., Liu, L., Wiens, B., Pond, P., 1996. Atmospheric Photochemistry of Naphthalene: a Practical and Theoretical Approach. Polycyclic Aromatic Compounds 9, 53-59. http://doi:10.1080/10406639608031201.

680 Lee, J., Lane, D.A., 2010. Formation of Oxidized Products from the Reaction of Gaseous Phenanthrene with the $\mathrm{OH}$ Radical in a Reaction Chamber. Atmospheric Environment 44, 2469 2477. http://doi:10.1016/j.atmosenv.2010.03.008.

Lei, Y.D., Wania, F., 2004. Is Rain or Snow a More Efficient Scavenger of Organic Chemicals? Atmospheric Environment 38, 3557-3571. http://doi:10.1016/j.atmosenv.2004.03.039.

685 Lei, Y.D., Wania, F., Shiu, W.Y., Boocock, D.G.B., 2000. HPLC-Based Method for Estimating the Temperature Dependence of n-Octanol-Water Partition Coefficients. Journal of Chemical \&. Engineering Data 45, 738-742. http://doi:10.1021/je9902488.

Leuenberger, C., Czuczwa, J., Heyerdahl, E., Giger, W., 1988. Aliphatic and Polycyclic Aromatic Hydrocarbons in Urban Rain, Snow and Fog. Atmospheric Environment 22, 695-705. http://doi:10.1016/0004-6981(88)90007-8. 
Liu, G., Tong, Y., Luong, J.H.T., Zhang H., Sun, H., 2010. A Source Study of Atmospheric Polycyclic Aromatic Hydrocarbons in Shenzhen, South China. Environmental Monitoring Assessments 163, 599-606. http://doi:10.1007/s10661-009-0862-4.

Lohmann, R., Lammel, G., 2004. Adsorptive and Absorptive Contributions to the Gas-Particle Partitioning of Polycyclic Aromatic Hydrocarbons: State of Knowledge and Recommended Parametrization for Modeling. Environmental Science and Technology 38, 3793-3803. http://doi:10.1021/es035337q.

Ma, J., Sverko, E., Su, Y., Zhang, J., Gao, H., 2013. Uptake and Mobilization of Organic Chemicals with Clouds: Evidence from a Hail Sample. Environmental Science and Technology 47, 9715-9721. http://doi:10.1021/es401401u.

Ma, Y., Lei, Y.D., Xiao, H., Wania, F., Wang, W., 2010. Critical Review and Recommended Values for the Physical-Chemical Property Data of 15 Polycyclic Aromatic Hydrocarbons at 25 ${ }^{\circ} \mathrm{C}$. Journal of Chemical \& Engineering Data 55, 819-825. http://doi:10.1021/je900477x.

Mallakin, A., Dixon, D.G., Greenberg, B.M., 2000. Pathway of Anthracene Modification Under Simulated Solar Radiation. Chemosphere 40, 1435-1441. http://doi:10.1016/S00456535(99)00331-8.

Mihele, C.M., Wiebe, H.A., Lane, D.A., 2002. Particle Formation and Gas/Particle Partition Measurements of the Products of the Naphthalene-OH Radical Reaction in a Smog Chamber. Polycyclic Aromatic Compounds 22, 729-736. http://doi:10.1080/10406630290103889.

710 Miller, J.S., Olejnik, D., 2001. Photolysis of Polycyclic Aromatic Hydrocarbons in Water. Water Research 35, 233-243. http://doi:10.1016/S0043-1354(00)00230-X.

Moza, P.N., Hustert, K., Kettrup, A., 1999. Photooxidation of Naphthalene and Phenanthrene in Hexane as an Oil Film on Water. Chemosphere 39, 569-574. http://doi:10.1016/S00456535(99)00122-8.

715 Niu, J., Chen, J., Martens, D., Quan, X., Yang, F., Kettrup, A., Schramm, K., 2003. Photolysis of Polycyclic Aromatic Hydrocarbons Adsorbed on Spruce [Picea abies (L.) Karst.] Needles Under Sunlight Irradiation. Environmental Pollution 123, 39-45. http://doi:10.1016/S02697491(02)00362-7.

Odabasi, M., Cetin, E., Sofuoglu, A., 2006. Determination of Ooctanol-Air Partition Coefficients and Supercooled Liquid Vapor Pressures of PAHs as a Function of Temperature: Application to Gas-Particle Partitioning in an Urban Atmosphere. Atmospheric Environment 40, 6615-6625. http://doi:10.1016/j.atmosenv.2006.05.051.

Parnis, J.M., Mackay, D., Harner, T., 2015. Temperature Dependence of Henry's Law Constants and KOA for Simple and Heteroatom-Substituted PAHs by COSMO-RS. Atmospheric Environment 110, 27-35. http://doi:10.1016/j.atmosenv.2015.03.032.

Pearlman R.S., Yalkowsky S.H., Banerjee S., 1984. Water Solubilities of Polynuclear Aromatic and Heteroaromatic Compounds. Journal of Physical Chemistry Reference Data 13, 555-562. http://doi:10.1063/1.555712. 
Pierlot, C. Aubry, J., 1997. First Evidence of the Formation of 5,8-Endoperoxide from the

730 Oxidation of 1,4-Disubstituted Naphthalene by Singlet Oxygen. Chemical Communications 23, 2289-2290. http://doi:10.1039/A705716D.

Plata, D.L., Sharpless, C.M., Reddy, C.M., 2008. Photochemical Degradation of Polycyclic Aromatic Hydrocarbons in Oil Films. Environmental Science and Technology 42, 2432-2438. http://doi:10.1021/es702384f.

735 Raja, S., Valsaraj, K.T., 2006. On the Reactive Uptake of Gaseous PAH Molecules by MicronSized Atmospheric Water Droplets. Atmospheric Research 81, 277-292. http://doi:10.1016/j.atmosres.2006.01.004.

Raja, S., Raghunathan, R., Yu, X., Lee, T., Chen, J., Kommalapati, R.R., Murugesan, K., Shen, X., Qingzhong, Y., Valsaraj, K.T., Collet Jr., J.L., 2008. Fog chemistry in the Texas-Louisiana

740 Gulf Coast corridor. Atmospheric Environment 42, 2048-2061. http://doi:10.1016/j.atmosenv.2007.12.004.

Reyes-Rodríguez, G.J., Gioda, A., Mayol-Bracero, O.L., Collett Jr., J.L., 2009. Organic Carbon, Total Nitrogen, and Water-Soluble Ions in Clouds from a Tropical Montane Cloud Forest in Puerto Rico. Atmospheric Environment 43, 4171-4177.

745 http://doi:10.1016/j.atmosenv.2009.05.049.

Reza, J., Trejo, A., 2004. Temperature Dependence of the Infinite Dilution Activity Coefficient and Henry's Law Constant of Polycyclic Aromatic Hydrocarbons in Water. Chemosphere 56, 537-547. http://doi:10.1016/j.chemosphere.2004.04.020.

Rogge, W.F., Hildemann, L., Mazurek, M.A., Cass, G.R., Simoneit, B.R.T., 1993. Sources of

750 Fine Organic Aerosol: 2. Noncatalyst and Catalyst-Equipped Automobiles and Heavy Duty Diesel Trucks. Environmental Science and Technology 27, 636-651. http://doi:10.1021/es00041a007.

Sanches, S., Leitão, C., Penetra, A., Cardoso, V.V., Ferreira, E., Benoliel, M.J., Barreto Crespo, M.T., Pereira, V.J., 2011. Direct Photolysis of Polycyclic Aromatic Hydrocarbons in Drinking

755 Water Sources. Journal of Hazardous Materials 192, 1458-1465. http://doi:10.1016/j.jhazmat.2011.06.065.

Sander, R., 2015. Compilation of Henry's Law Constants (version 4.0) for Water as Solvent. Atmospheric Chemistry and Physics 15, 4399-4981. http://doi:10.5194/acp-15-4399-2015.

Shahpoury, P., Lammel, G., Holubová Šmejkalová, A., Klánová, J., Přibylová, P., Váňa, M., 760 2015. Polycyclic Aromatic Hydrocarbons, Polychlorinated Biphenyls, and Chlorinated Pesticides in Background Air in Central Europe - Investigating Parameters Affecting Wet Scavenging of Polycyclic Aromatic Hydrocarbons. Atmospheric Chemistry and Physics 15, 1795-1805. http://doi:10.5194/acp-15-1795-2015.

Sigman, M.E., Chevis, E.A., Brown, A., Barbas, J.T., Dabestani, R., Burch E.L., 1996. Enhanced 765 Photoreactivity of Acenaphthylene in Water: A Product and Mechanism Study. Journal of Photochemistry and Photobiology A 94, 149-155. http://doi:10.1016/1010-6030(95)04099-4.

Škrdlíková, L., Landlová, L., Klánová, J., Lammel, G., 2011. Wet Deposition and Scavenging Efficiency of Gaseous and Particulate Phase Polycyclic Aromatic Compounds at a Central 
European Suburban Site. Atmospheric Environment 45, 4305-4312.

770 http://doi:10.1016/j.atmosenv.2011.04.072.

Styler, S.A., Loiseaux, M.-E., Donaldson, D.J., 2011. Substrate Effects in the Photoenhanced Ozonation of Pyrene. Atmospheric Chemistry and Physics 11, 1243-1253.

http://doi:10.5194/acp-11-1243-2011.

Table 1. Dose Response Assessment Tables; United States Environmental Protection Agency,

775 May 9, 2014; www2.epa.gov/sites/production/files/2014-05/documents/table1.pdf (accessed Jan 19, 2015)

ten Hulscher, Th. E.M., van der Velde, L.E., Bruggeman, W.A., 1992. Temperature Dependence of Henry's Law Constants for Selected Chlorobenzenes, Polychlorinated Biphenyls and Polycyclic Aromatic Hydrocarbons. Environmental Toxicology \& Chemistry 11, 1595-1603.

780 http://doi:10.1002/etc.5620111109.

Valsaraj, K.T., 2004. Adsorption of Polycyclic Aromatic Hydrocarbons at the Air-Water Interface and its Role in Atmospheric Deposition by Fog Droplets. Environmental Toxicology and Chemistry 23, 2318-2323. http://doi:10.1897/03-321.

Valsaraj, K.T., 2009. Trace Gas Adsorption Thermodynamics at the Air-Water Interface:

785 Implications in Atmospheric Chemistry. Pure and Applied Chemistry 81, 1889-1901. http://doi:10.1351/PAC-CON-08-07-06.

Walters R. W. and R. G. Luthy, 1984, Equilibrium adsorption of polycyclic aromatic hydrocarbons from water onto activated carbon, Environmental Science \& Technology, 18, 6, 395-403, doi: 10.1021/es00124a002

790 Wang, L., Atkinson, R., Arey, J., 2007. Formation of 9,10-Phenanthrenequinone by Atmospheric Gas-Phase Reaction of Phenanthrene. Atmospheric Environment 41, 2025-2035. http://doi:10.1016/j.atmosenv.2006.11.008.

Wang, L., Wang, X., Xu, O., Tian, L., 1986. Determination of the N-Octanol/Water Partition Coefficients of Polycyclic Aromatic Hydrocarbons and Estimation of Aqueous Solubilities. Acta 795 Scientiae Circumstantiae 6, 491-497.

Whitehouse, B.G., 1984. The Effects of Temperature and Salinity on the Aqueous Solubility of Polynuclear Aromatic Hydrocarbons. Marine Chemistry 14, 319-332. http://doi:10.1016/03044203(84)90028-8.

Woo, O.T., Chung, W.K., Wong, K.H., Chow, A.T., Wong, P.K., 2009. Photocatalytic Oxidation 800 of Polycyclic Aromatic Hydrocarbons: Intermediates Identification and Toxicity Testing. Journal of Hazardous Materials 168, 1192-1199. http://doi:10.1016/j.jhazmat.2009.02.170.

Yap, C.L., Gan, S., Ng, H.K., 2012. Evaluation of Solubility of Polycyclic Aromatic Hydrocarbons in Ethyl Lactate/Water Versus Ethanol/Water Mixtures for Contaminated Soil Remediation Applications. Journal of Environmental Sciences 24, 1064-1075.

805 http://doi:10.1016/S1001-0742(11)60873-5.

Zak, J.A., 1994. Drop Size Distributions and Related Properties of Fog for Five Locations Measured from Aircraft; NASA Contractor Report 4585; DOT/FAA/CT-94/02; National Aeronautics and Space Administration, Langley Research Center: Hampton, VA, 136. 
Zepp, R., Schlotzhauer, P., 1979. Photoreactivity of Selected Aromatic Hydrocarbons in Water, 810 In Jones, P., Leber, P. (Eds.), Polynuclear Aromatic Hydrocarbons, Ann Arbor Science Publishers, Ann Arbor, MI, 141-158.

Zimmermann, R., L. Vaeck, Van, M.Davidovic, , M.Beckmann, F.Adams, Analysis of Polycyclic Aromatic Hydrocarbons (PAH) Adsorbed on Soot Particles by Fourier Transform Laser Microprobe Mass Spectrometry (FT LMMS): Variation of the PAH Pattern, 815 Environmental Science \& Technology, 34, 22, 4780-4788, doi: 10.1021/es0000596

Zhang, Y., Tao, S., 2009. Global Atmospheric Emission Inventory of Polycyclic Aromatic Hydrocarbons (PAHs) for 2004. Atmospheric Environment 43, 812-819. http://doi:10.1016/j.atmosenv.2008.10.050. 
Graphical abstract:

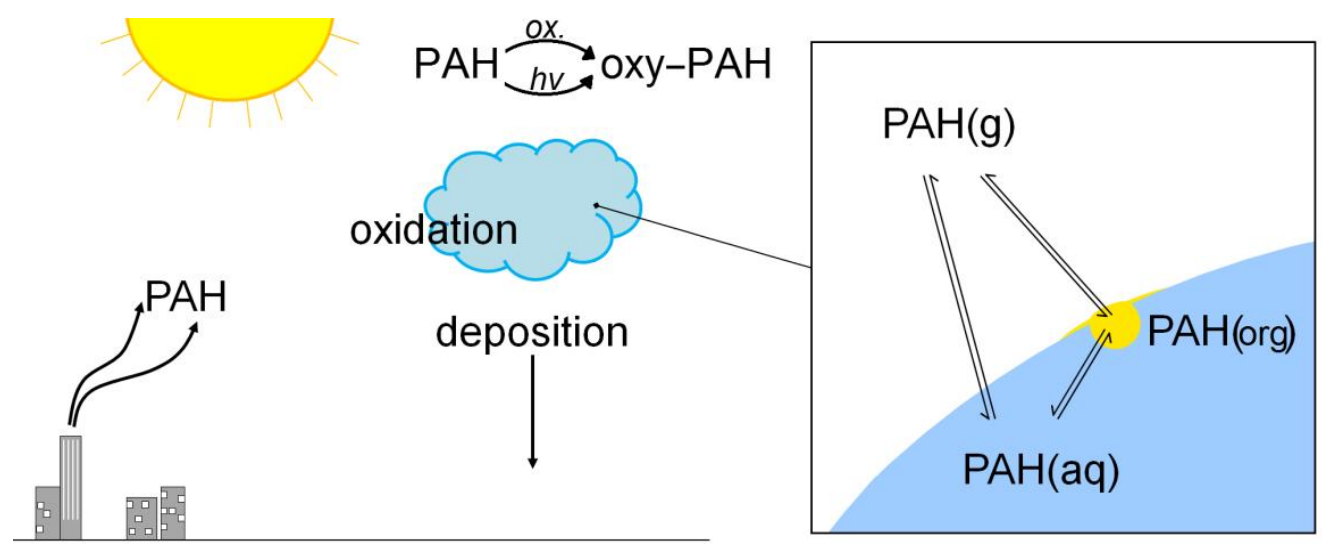

